\title{
A Theoretical Study of Methanol Vinylation Reaction Mechanism
}

\author{
NADEZHDA M. VITKOVSKAYA, ${ }^{1}$ ELENA YU. LARIONOVA, ${ }^{1}$ \\ VLADIMIR B. KOBYCHEV, ${ }^{1}$ NATALIA V. KAEMPF, ${ }^{1}$ \\ BORIS A. TROFIMOV ${ }^{2}$ \\ ${ }^{1}$ Laboratory of Quantum Chemistry, Irkutsk State University, 664003 Irkutsk, Russia \\ ${ }^{2}$ A. E. Favorsky Irkutsk Institute of Chemistry, Siberian Branch of the Russian Academy of Sciences, \\ 664033 Irkutsk, Russia
}

Received 30 November 2007; accepted 14 January 2008

Published online 12 March 2008 in Wiley InterScience (www.interscience.wiley.com).

DOI 10.1002/qua.21639

\begin{abstract}
The mechanism of base-catalyzed nucleophilic addition of methanol to acetylene triple bond (vinylation) in dimethyl sulfoxide (DMSO) and methanol solution was studied using the MP2/6-311++G**//B3LYP/6-31G* calculations with solvent effects included via continuum model. The proton abstraction from methanol by nondissociated alkali in DMSO surrounding media to form alkali metal methoxides $\mathrm{CH}_{3} \mathrm{OM}(\mathrm{M}=\mathrm{Li}, \mathrm{Na}, \mathrm{K})$ was found to occur with a negligible activation barrier. The reasons for facilitation of base-catalyzed alcohol vinylation in the DMSO medium are discussed in the light of both poor solvation of methoxide ion and a specific coordination of reactants by nondissociated alkali in the $\mathrm{MOH} / \mathrm{DMSO}$ mixtures. (ㅇ 2008 Wiley Periodicals, Inc. Int J Quantum Chem 108: 2630-2635, 2008
\end{abstract}

Key words: methanol; acetylene; vinylation; dimethyl sulfoxide; reaction mechanism

\section{Introduction}

V inyl ethers and derived polymers are particularly useful in formulating adhesives and coating additives. The copolymer of methyl vinyl ether and maleic anhydride sold by General Aniline and Film Corporation under the name GantrezAN

Correspondence to: V. B. Kobychev; e-mail: gimli@cc.isu.ru Contract grant sponsor: Russian Foundation for Basic Researches.

Contract grant number: 06-03-32397. series [1] are important in hair sprays and shampoos and compete with the polyvinylpyrrolidone polymers as versatile specialty polymers. Polyvinyl methyl ether and copolymers have various uses as adhesives, particularly in high-tack formulations.

Vinyl ether monomers are prepared by the basecatalyzed reaction of alcohols with acetylene

$$
\mathrm{C}_{2} \mathrm{H}_{2}+\mathrm{ROH} \rightarrow \mathrm{RO}-\mathrm{CH}=\mathrm{CH}_{2} \text {. }
$$

The original Reppe process [2, 3] requires the pressure as high as 20-22 atm, sometimes up to 60 
atm [4], and the temperature up to $165^{\circ} \mathrm{C}$; acetylene usually being diluted by nitrogen.

Recent advances in direct base-catalyzed vinylation by acetylene are associated with the application of superbase catalytic media [5-8]. Typically, these catalysts consist of a strong base and a strongly polar nonhydroxylic complexing solvent. The feature of these media is a specific cation solvation and a poor solvation of anions that provides the increased activity of the latter. The most foolproof, safe, available, and active superbasic catalysts for vinylation with acetylene are the alkali metal hydroxides-dimethyl sulfoxide (DMSO) systems. Generally, these catalytic media enable avoiding pressure and decrease temperature essentially in diverse vinylation processes. For instance, the modern vinylation process of methanol or other lower alcohols [9] operates under atmospheric pressure and at a temperature as low as $80-100^{\circ} \mathrm{C}$, with no diluent of acetylene. The yield of methyl vinyl ether is almost quantitative.

The base-catalyzed addition of compounds with an acidic hydrogen to any acetylenic compound, vinylation, has been widely applied in syntheses. Nevertheless, a detailed mechanism of vinylation reaction and the origin of superbase media catalytic activity are not evident up to date.

Miller and Shkapenko [10] have studied the kinetics of the methoxide-catalyzed addition of methanol to phenylacetylene in the solvents, methanol and dioxane. The reaction appears to be first order in phenylacetylene, first order in methoxide, and zero order in methanol. These data are consistent with the following general mechanism: the ratedetermining step is the addition of alkoxide ion to the acetylene

$$
\mathrm{H}_{3} \mathrm{CO}^{-}+\mathrm{HC} \equiv \mathrm{CH} \rightarrow \mathrm{H}_{3} \mathrm{CO}-\mathrm{CH}=\mathrm{CH}^{-} \text {. }
$$

This is followed by the rapid abstraction of a proton from the alcohol by the carbanion intermediate

$$
\begin{aligned}
& \mathrm{H}_{3} \mathrm{CO}-\mathrm{CH}=\mathrm{CH}^{-} \\
& \quad+\mathrm{CH}_{3} \mathrm{OH} \rightarrow \mathrm{H}_{3} \mathrm{CO}-\mathrm{CH}=\mathrm{CH}_{2}+\mathrm{H}_{3} \mathrm{CO}^{-} .
\end{aligned}
$$

However, the activity of $\mathrm{MOH} / \mathrm{DMSO}$ superbase catalytic media in vinylation reactions depends on the nature of alkali metal. For instance, the catalytic activity of alkali metal hydroxides in base-catalyzed addition of 1-heptanol to acetylene decreases in the series $2 \mathrm{KOH} \cdot \mathrm{H}_{2} \mathrm{O}>\mathrm{RbOH} \cdot \mathrm{H}_{2} \mathrm{O}>\mathrm{CsOH} \cdot \mathrm{H}_{2} \mathrm{O}>$
$\mathrm{NaOH}$ [11]. In particular, this is associated with the acetylene activation under coordination to alkali metal cation or nondissociated alkali molecule [12]. Indeed, alkalis poorly dissolve, and hence poorly dissociate in DMSO. For instance, the $\mathrm{MOH}$ dissociation constant decreases from $\mathrm{K}=7.9 \times 10^{-4}$ in $\mathrm{KOH}$ to $\mathrm{K}=2.0 \times 10^{-5}$ for $\mathrm{NaOH}$, and $K=1.2 \times$ $10^{-6}$ in $\mathrm{LiOH}$ solution [13]. Here, we present a theoretical study of the methanol vinylation mechanism in the DMSO solution in the presence of alkali metal hydroxides, considering a DMSO surrounding within a continuum model.

\section{Computational Details}

The reaction profiles for methanol vinylation process were obtained within a combined computational procedure using GAMESS [14] and Gaussian-98 [15] programs:

i. The preliminary calculations of the stationary points under discussion were performed using the RHF/6-31+ $\mathrm{G}^{*}$ approach in a gas phase. The number of negative Hessian eigenvalues was checked for all the stationary points found. The connection of the transition states (TSs) with corresponding minima was proved by following the intrinsic reaction coordinate using Gonzalez and Schlegel technique [16]. Finally, the standard Gaussian-98 procedure related to the "Volume" keyword was employed to estimate radii for use with the Onsager solvent reaction field model.

ii. Further reoptimization was carried out with solvent effect included via Kirkwood and Onsager self-consistent reaction field (SCRF) model [17-19]. The same $6-31+G^{*}$ basis set was used in DFT calculations with a hybrid Becke's three-parameter exchange functional [20], and the gradient-corrected functional [21] of Lee et al. (B3LYP/6-31+G*). The B3LYP /6-31+ $G^{*}$ (SCRF) force constants, and the resulting vibration frequencies were used for the further thermochemistry analysis.

iii. A B3LYP/6-31+ $\mathrm{G}^{*}$ geometry was used to calculate solvation energies within the polarizable continuum model (PCM) in the integral IEFPCM formulation [22] (RHF/6$\left.31+\mathrm{G}^{*}\right)$. A standard UATM [23] cavity as implemented in Gaussian-98 was used for methanol solvent, while Almerindo et al. 
[24]. atomic radii $1.20(\mathrm{H}), 1.50(\mathrm{O})$, and 1.70

(C) combined with cationic (instead of van der Waals or atomic) radii $1.00(\mathrm{Li}), 1.25(\mathrm{Na})$, and $1.60(\mathrm{~K})$ obtained from the united atom topological model were used for a DMSO solution with a uniform scale factor of 1.35 [24].

iv. Finally, the MP2/6-311+ $+\mathrm{G}^{* *} / / \mathrm{B} 3 \mathrm{LYP} / 6-$ $31+\mathrm{G}^{*}(\mathrm{SCRF})$ energies were combined with the B3LYP $/ 6-31+\mathrm{G}^{*}(\mathrm{SCRF})$ zero-point energy, enthalpy, and Gibbs free energy corrections and RHF/6-31+G* IEFPCM solvation energies.

\section{Results and Discussion}

We start our consideration with the interaction between nondissociated $\mathrm{MOH}$ hydroxide $(\mathrm{M}=\mathrm{Li}$, $\mathrm{Na}, \mathrm{K}$ ) and methanol molecule. In the DMSO solution, this interaction results first in a stable $\mathrm{H}_{3} \mathrm{COH} \cdot \mathrm{MOH}$ complex (1) with an oxygen atom $\mathrm{O}^{(2)}$ of alcohol coordinated to alkali metal atom $\mathrm{M}^{(4)}$ and the methanol hydroxyl $\mathrm{H}^{(3)}$ atom oriented to $\mathrm{O}^{(5)}$ oxygen atom of hydroxide (See Fig. 1). The $\mathrm{H}^{(3)}-\mathrm{O}^{(5)}$ distance $(1.798,1.548$, and $1.485 \AA$ for $M=\mathrm{Li}, \mathrm{Na}, \mathrm{K}$, respectively) decreases in the series by $0.313 \AA$, as well as $\mathrm{H}^{(3)} \mathrm{O}^{(5)} \mathrm{H}^{(6)}$ bond angle $\left(138.6^{\circ}, 125.9^{\circ}\right.$, and $119.4^{\circ}$ for $\mathrm{M}=\mathrm{Li}, \mathrm{Na}, \mathrm{K}$, respectively). Thus, the $\mathrm{KOH}$ coordination provides the most favorable disposition for $\mathrm{H}^{(3)}$... $\mathrm{O}^{(5)}$ hydrogen bond formation, and the potassium complex $\mathbf{1}$ is the most stable $(\Delta H=-1.8,-6.5$, and $-11.2 \mathrm{kcal} / \mathrm{mol}$ for $\mathrm{LiOH}, \mathrm{NaOH}$, and $\mathrm{KOH}$, respectively). Simultaneously, the methanol $\mathrm{O}^{(2)}-\mathrm{H}^{(3)}$ bond distance in $\mathbf{1}$ increases with respect to one in solvated $\mathrm{CH}_{3} \mathrm{OH}$, reflecting weakening of this bond under coordination. The bond lengthening also increases in the series $\mathrm{Li}<\mathrm{Na}<\mathrm{K}(0.030,0.068$, and $0.087 \AA$, respectively). Hence, coordination by $\mathrm{MOH}$ facilitates further alcohol transformation, and this effect is the most pronounced in $\mathrm{KOH} / \mathrm{DMSO}$ media.

The pathway of $\mathrm{H}^{(3)}$ proton relocation from $\mathrm{O}^{(2)}$ to $\mathrm{O}^{(5)}$ passes TS 2 with about equal $\mathrm{O}-\mathrm{H}$ distances (See Fig. 1). The TS's for all the systems under discussion have exactly one negative Hessian eigenvalue. The imaginary frequencies are 1032.5i, $793.9 i$, and $680.1 i \mathrm{~cm}^{-1}$ for $M=\mathrm{Li}, \mathrm{Na}, \mathrm{K}$, respectively, and the $\mathrm{H}^{(3)}$ motion brings a dominant contribution to the transition vector. The proton transfer activation barriers calculated with no vibration correction are small $(1.2-1.4 \mathrm{kcal} / \mathrm{mol})$ in all the $M=\mathrm{Li}, \mathrm{Na}, \mathrm{K}$ series. Thus, a proton transfer from the alcohol molecule to alkali metal hydroxide in the $\mathrm{CH}_{3} \mathrm{OH} / \mathrm{MOH} / \mathrm{DMSO}$ system occurs with almost no activation barrier.

Following the reaction coordinate, the system turns into complex $\mathrm{CH}_{3} \mathrm{OM} \cdot \mathrm{H}_{2} \mathrm{O}$ (3) of alkali metal methoxide and the water molecule formed in the proton transfer process. The $\cdot \mathrm{H}_{2} \mathrm{O}$ molecule in 3 is coordinated to metal atom with its $\mathrm{O}^{(5)}$ oxygen, while the $\mathrm{H}^{(3)}$ hydrogen forms a hydrogen $\mathrm{O} \cdots \mathrm{H}$ bond with methoxide oxygen atom $\mathrm{O}^{(2)}$. The $\mathrm{O}^{(2)}-\mathrm{H}^{(3)}$ distances in 3 are much shorter than hydrogen bonds in water dimer, $1.87 \AA$ [25], and decrease in the series $\mathrm{Li}>\mathrm{Na}>\mathrm{K}(1.798,1.586$, and $1.522 \AA$, respectively). On the contrary, the $\mathrm{M}^{(4)}$ $\mathrm{O}^{(5)}$ distance is about $0.2 \AA$ larger than that in 1 , and increases in the $\mathrm{Li}<\mathrm{Na}<\mathrm{K}$ series $(1.921,2.289$, and $2.682 \AA$, respectively). So, the water molecule is mainly located near the metal atom in lithium system, and shifts toward a methoxy group oxygen when interacting with potassium methoxide.

The presence of even an only water molecule causes a significant lengthening of the $\mathrm{M}-\mathrm{O}$ bond of alkali methoxide moiety in 3 with respect to one in separate $\mathrm{CH}_{3} \mathrm{OM}$. In a gas phase, the $\mathrm{M}-\mathrm{O}$ bond distance in $\mathrm{CH}_{3} \mathrm{OM} \cdot \mathrm{H}_{2} \mathrm{O}$ increases by $0.072,0.087$,

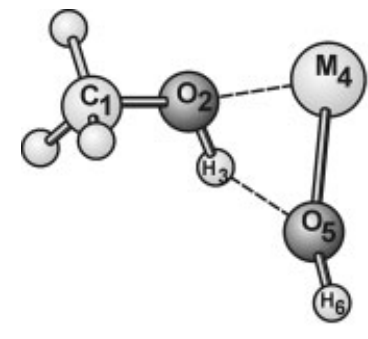

1

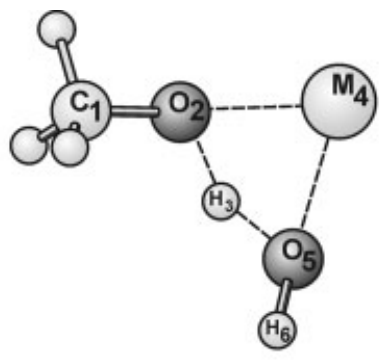

2

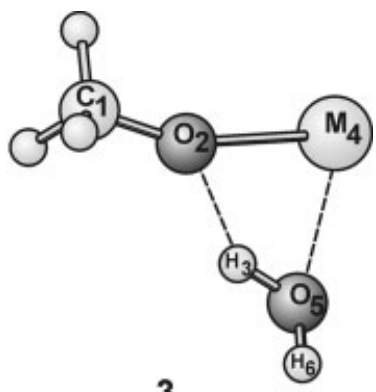

3

FIGURE 1. Characteristic structures of the $\mathrm{CH}_{3} \mathrm{OH}+\mathrm{MOH} \rightarrow \mathrm{CH}_{3} \mathrm{OM} \cdot \mathrm{H}_{2} \mathrm{O}$ reaction profile. 


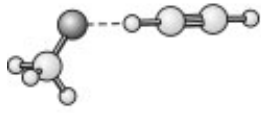

4

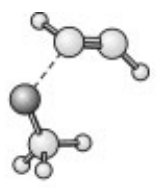

5

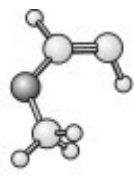

6

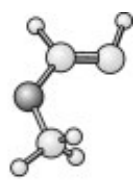

7
FIGURE 2. Characteristic structures of the $\mathrm{CH}_{3} \mathrm{O}^{-}+$ $\mathrm{C}_{2} \mathrm{H}_{2} \rightarrow \mathrm{CH}_{3} \mathrm{OCH}=\mathrm{CH}^{-}$reaction profile.

and $0.104 \AA$ when $M=\mathrm{Li}, \mathrm{Na}$ and $\mathrm{K}$, respectively. In the DMSO solution, this effect is less pronounced but yet marked; the $\mathrm{K}-\mathrm{O}$ bond distance remains the most elongated by $0.091 \AA$. This indicates a specific weakening of the $\mathrm{K}-\mathrm{O}$ bond that promotes a soluted methoxide ion formation.

The first stage of the methoxide ion nucleophilic attack to the acetylene molecule results in the ionmolecular complex 4 (See Fig. 2). In the DMSO environment, 4 is stable with respect to dissociation to solvated $\mathrm{CH}_{3} \mathrm{O}^{-}$and acetylene; the dissociation energy found in our calculations is $-4.9 \mathrm{kcal} / \mathrm{mol}$. Having in mind a close acidity of methanol and acetylene in both gas phase and DMSO solution [26, 27], one could expect 4 to be a precursor of acetylenide ion. Indeed, an "acidic" hydrogen atom is relatively close to methoxide oxygen, the $\mathrm{O} \cdots \mathrm{H}$ distance in 4 is $1.701 \AA$, while the $\mathrm{C}-\mathrm{H}$ bond length increases by $0.07 \AA$. Nevertheless, the minimum 4 on the potential energy surface was proved to belong to the vinylation reaction pathway in both gas phase [28] and DMSO solution (this work).

Following the reaction coordinate, the ion-molecular complex 4 passes a TS $5\left(\nu_{\mathrm{im}}=283.0 i\right)$ with a trans-bent acetylene moiety to form an E-methoxyethenide carbanion 6 (See Fig. 2). Though a $Z$-isomer 7 of methoxyethenide ion is the most stable and differs in energy by $1.1 \mathrm{kcal} / \mathrm{mol}$ from $E$-isomer, the corresponding TS with a cis-bent acetylene was found to be $6.7 \mathrm{kcal} / \mathrm{mol}$ higher in a gas-phase reaction [28]. The similar result occurred in the theoretical study of pyrrole anion addition to acetylene for both gas phase and DMSO solution [29]. These account for a well known Z-stereoselectivity of the nucleophilic addition to monosubstituted acetylenes [10]. Therefore, the present study is restricted to considering $E$-metoxyethene ion formation in the SP-conformation known to be the most stable in both metoxyethene and its anion [30, 31].

The reaction profile obtained (See Fig. 3) displays an endothermic character of this stage: the reaction [1] enthalpy in DMSO solution is $\Delta H=2.5 \mathrm{kcal} /$ mol. The inner activation barrier for the ion-molecular complex 4 rearrangement toward methoxyethenide ion 6 is $\Delta H_{\text {inner }}^{\#}=16.4 \mathrm{kcal} / \mathrm{mol}$, and the overall activation barrier is $\Delta H^{\#}=11.5$ $\mathrm{kcal} / \mathrm{mol}$.

The calculated solvation energy of methoxide ion in methanol solution, $-87.6 \mathrm{kcal} / \mathrm{mol}$, is far above than that in DMSO, $-68.6 \mathrm{kcal} / \mathrm{mol}$. This results in both quantitative and qualitative changes in the reaction profile of methoxide ion nucleophilic addition to acetylene in methanol surrounding (See Fig. 3). The activation barrier $\Delta H^{\#}$ in methanol solution grows up to $18.0 \mathrm{kcal} / \mathrm{mol}$. No analog of ion-molecular complex 4 was found for methanol solution: the energy of corresponding structure is $2.6 \mathrm{kcal} / \mathrm{mol}$ higher than sum of separate acetylene and methoxide ion. The other peculiarity of the reaction profile in methanol solution is a very small activation barrier of the methoxyethenide ion dissociation, $0.4 \mathrm{kcal} / \mathrm{mol}$ (See Fig. 3). Taken together, the above gives reasons for facilitation of basecatalyzed alcohol vinylation process in the DMSO surrounding medium.

Proton abstraction from the alcohol by the carbanion intermediate 6 (Eq. 2) accomplishes the process of methanol vinylation. No activation barrier was found on the pathway of methanol molecule interaction with methoxyethenide ion yielding ionmolecular complex 8 (See Fig. 4) in the DMSO solution. This stage is exothermic by $-25.5 \mathrm{kcal} /$ $\mathrm{mol}$, and the overall vinylation reaction heat found is $\Delta H=23.0 \mathrm{kcal} / \mathrm{mol}$. These give reasons for a

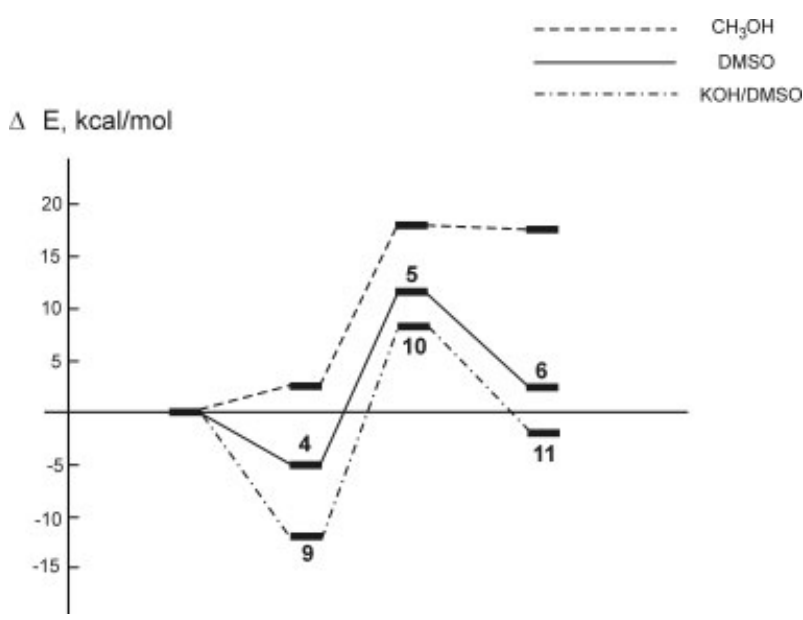

FIGURE 3. Reaction profile scheme for methoxide ion nucleophilic addition to acetylene $\mathrm{CH}_{3} \mathrm{O}^{-}+\mathrm{C}_{2} \mathrm{H}_{2} \rightarrow$ $\mathrm{CH}_{3} \mathrm{OCH}=\mathrm{CH}^{-}$in methanol, dimethyl sulfoxide and $\mathrm{KOH} / \mathrm{DMSO}$ system. 


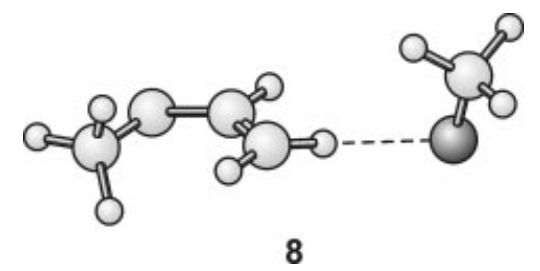

FIGURE 4. Ion-molecular complex 8 of methyl vinyl ether with methoxide ion.

kinetic formation of less stable Z-isomers in vinylation of substituted acetylenes caused by significantly less activation barrier for the less stable carbanion intermediate mentioned above.

Although alkali metal hydroxides dissociate readily in methanol, they are poorly dissociated in $\mathrm{MOH}-\mathrm{DMSO}$ mix. This gives rise to considering alcohol vinylation mechanism, involving nondissociated $\mathrm{MOH}$ in DMSO environment.

Acetylene, methoxide ion, and alkali molecule $\mathrm{MOH}$ in DMSO combine into stable complexes 9 (See Fig. 5) bounded with respect to contaminants by $-19.1,-12.6$, and $-12.4 \mathrm{kcal} / \mathrm{mol}$ for $M=\mathrm{Li}$, $\mathrm{Na}, \mathrm{K}$ in that order. Mutual positions of the $\mathrm{HC} \equiv \mathrm{CH}$ molecule and methoxide ion in $\mathbf{9}$ are similar to that in ion-molecular complex 4. Although the acetylene-methoxide ion binding energy in 4 is $4.8 \mathrm{kcal} / \mathrm{mol}$, the energy of $\mathrm{HC} \equiv \mathrm{CH}$ interaction with anionic $\mathrm{MOH} \cdot\left[\mathrm{OCH}_{3}\right]^{-}$substrate drops down to $2.5 \mathrm{kcal} / \mathrm{mol}$ when $M=\mathrm{Li}$. In the complex 9 with $\mathrm{NaOH}$, the acetylene moiety is still less bounded when compared to $4(3.8 \mathrm{kcal} / \mathrm{mol})$, while the potassium hydroxide helps acetylene complex stabilization, and the $\mathrm{C}_{2} \mathrm{H}_{2}-\mathrm{KOH} \cdot\left[\mathrm{OCH}_{3}\right]^{-}$interaction energy reaches $5.3 \mathrm{kcal} / \mathrm{mol}$.

A methoxide ion nucleophilic addition to acetylene in the presence of alkali in DMSO passes TS $\mathbf{1 0}$ to form complex $\mathbf{1 1}$ of methoxyethenyde ion with $\mathrm{MOH}$. The character of $\mathbf{1 1}$ is a relative stabilization of the $A C$-conformation of anionic intermediate by alkali metal hydroxide joined to both negatively charged ether oxygen and terminal vinyl carbon (See Fig. 5). The most stable in $6 S P$-conformation (See Fig. 2) turns to be less stable in 11, when coordinated to $\mathrm{MOH}$ with ether oxygen atom.

Hence, the $A C$-structure of $\mathbf{1 1}$ is the most stable as well as the corresponding structure of $\mathbf{1 0}\left(\nu_{\mathrm{im}}=\right.$ $618.1 i$ for a potassium containing system). In the $\mathrm{C}_{2} \mathrm{H}_{2} / \mathrm{CH}_{3} \mathrm{O}^{-} / \mathrm{KOH} / \mathrm{DMSO}$ system, the inner activation barrier increases to $20.7 \mathrm{kcal} / \mathrm{mol}$. Nevertheless, the overall activation barrier in the presence of nondissociated $\mathrm{KOH}$ decreases from 11.5 to 8.3 $\mathrm{kcal} / \mathrm{mol}$ (See Fig. 3). Furthermore, while the carbanionic intermediate 6 formation is an endothermic process, the energy of $\mathbf{1 1}$ falls below the energy sum of reactants. The overall heat of this reaction stage is $\Delta H=-2.1 \mathrm{kcal} / \mathrm{mol}$. Hence, a coordination by a nondissociated alkali could cause further facilitation of the vinylation process in DMSO solution.

Similar to separate 6 , proton abstraction from the alcohol by a methoxyethenyde ion coordinated to $\mathrm{KOH}$ in $\mathbf{1 1}$ occurs with no activation barrier, and is accompanied by further energy decrease by $\Delta H=$ $-28.2 \mathrm{kcal} / \mathrm{mol}$.

\section{Conclusions}

The mechanism of base-catalyzed nucleophilic addition of methanol to acetylene in DMSO and methanol solution was studied using the MP2/6$311++\mathrm{G}^{* *} / /$ B3LYP $/ 6-31 \mathrm{G}^{*}$ calculations, with solvent effects included via SCRF and IEFPCM continuum model.

The proton abstraction from methanol by nondissociated alkali in DMSO environs to form alkali metal methoxides $\mathrm{CH}_{3} \mathrm{OM}(\mathrm{M}=\mathrm{Li}, \mathrm{Na}, \mathrm{K})$ was found to occur with a negligible activation barrier.

A poor solvation of methoxide ion in DMSO in comparison with one in methanol decreases the activation barrier of intermediate methoxyethenyde ion formation. Further decrease of the TS energy in DMSO with respect to reactants could be caused by coordination of the latter by a nondissociated alkali. These give reasons for facilitation of base-catalyzed alcohol vinylation process in the DMSO medium.

No activation barrier was found on the pathway of proton abstraction from the alcohol by the carbanion intermediate. These contribute to a kinetic formation of less stable Z-isomers in vinylation of substituted acetylenes.
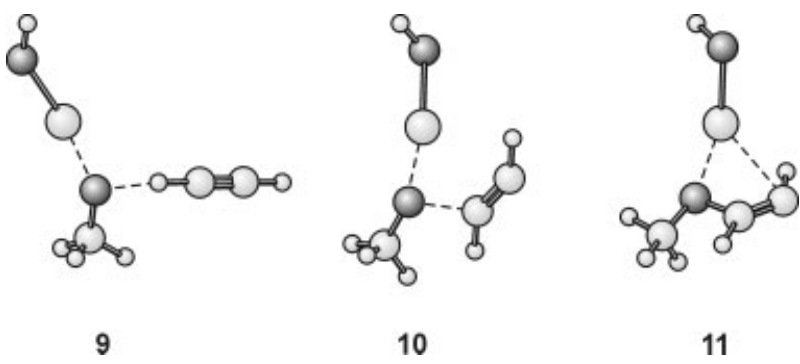

FIGURE 5. Characteristic structures of the $\mathrm{CH}_{3} \mathrm{O}^{-}+$ $\mathrm{C}_{2} \mathrm{H}_{2} \rightarrow \mathrm{CH}_{3} \mathrm{OCH}=\mathrm{CH}^{-}$reaction profile in the presence of nondissociated alkali. 


\section{References}

1. Tedeschi, R. J. Acetylene. In Encyclopedia of Physical Science and Technology, 3rd ed.; Academic Press, 2001; p 55.

2. Reppe, W. Neue Entwicklungen auf dem Gebiete der Chemie des Acetylens und Kohlenoxyds; Springer-Verlag: Berlin-Gottingen-Heidelberg, 1949.

3. Copenhaver, J. W.; Bigelow, M. H. Acetylene and Carbon Monoxide Chemistry; Reinhold Publishing Corp.: New York, 1949.

4. Shostakovsky, M. F. Simple Vinyl Ethers; Izdatel'stvo Akademii Nauk SSSR: Moscow, 1952 (in Russian).

5. Trofimov, B. A. Usp Khim 1981, 50, 248; (Chem Abstr, 1981, 94, 207925s).

6. Trofimov, B. A. Z Chem 1986, 26, 41.

7. Trofimov, B. A. Zh Org Khim 1986, 22, 1991; (Chem Abstr, 1987, 107, 77247w).

8. Trofimov, B. A. Zh Org Khim 1995, 31, 1368; (Chem Abstr, $1996,125,36228 \mathrm{u})$.

9. Trofimov, B. A.; Oparina, L. A.; Lavrov, V. I.; Parshina, L. N RF Pat 1504969 (1986).

10. Miller, S. I.; Shkapenko G. J Am Chem Soc 1955, 81, 5038.

11. Parshina, L. N.; Oparina, L. A.; Gorelova, O. V.; Preiss, T.; Henkelmann, J.; Trofimov, B. A. Zh Org Khim 2001, 37, 940.

12. Trofimov, B. A. Curr Org Chem 2002, 6, 1121.

13. Vasil'tsov, A. M.; Trofimov, B. A.; Amosova, S. V. Russ Chem Bull 1987, 36, 1653.

14. Schmidt, M. W.; Baldridge, K. K.; Boatz, J. A.; Elbert, S. T.; Gordon, M. S.; Jensen, J. H.; Koseki, S.; Matsunaga, N.; Nguyen, K. A.; Su, S. J.; Windus, T. L.; Dupius, M.; Montgomery, J. A. J Comput Chem 1993, 14, 1347.

15. Frisch, M. J.; Trucks, G.W.; Schlegel, H. B.; Scuseria, G. E.; Robb, M. A.; Cheeseman, J. R.; Zakrzewski, V. G.; Montgomery, J. A., Jr, Stratmann, R. E.; Burant, J. C.; Dapprich, S.; Millam, J. M.; Daniels, A. D.; Kudin, K. N.; Strain, M. C.;
Farkas, O.; Tomasi, J.; Barone, V.; Cossi, M.; Cammi, R.; Mennucci, B.; Pomelli, C.; Adamo, C.; Clifford, S.; Ochterski, J.; Petersson, G. A.; Ayala, P. Y.; Cui, Q.; Morokuma, K.; Malick, D. K.; Rabuck, A. D.; Raghavachari, K.; Foresman, J. B.; Cioslowski, J.; Ortiz, J. V.; Stefanov, B. B.; Liu, G.; Liashenko, A.; Piskorz, P.; Komaromi, I.; Gomperts, R.; Martin, R. L.; Fox, D. J.; Keith, T.; Al-Laham, M. A.; Peng, C. Y.; Nanayakkara, A.; Gonzalez, C.; Challacombe, M.; Gill, P. M. W.; Johnson, B.; Chen, W.; Wong, M. W.; Andres, J. L.; Gonzalez, C.; Head-Gordon, M.; Replogle, E. S.; Pople, J. A. Gaussian 98, Revision A. 6, Gaussian: Pittsburgh PA, 1998.

16. Gonzalez, C.; Schlegel, H.B. J Phys Chem 1990, 94, 5523.

17. Onsager, L. J Am Chem Soc 1936, 58, 1486.

18. Kirkwood, J. G. J Chem Phys 1934, 2, 351.

19. Tapia, O.; Goscinski, O. Mol Phys 1975, 29, 1653.

20. Becke, A. D. J Chem Phys 1993, 98, 5648.

21. Lee, C.; Yang, W.; Parr R. G. Phys Rev B 1988, 37, 785.

22. Tomasi, J.; Mennucci, B.; Cancès, E. J Mol Struct (Theochem) 1999, 464, 211.

23. Barone, V.; Cossi, M.; Tomasi, J. J Chem Phys 1997, 107, 3210.

24. Almerindo, G. I.; Tondo, D. W.; Pliego, J. R., Jr. J Phys Chem A 2004, 108, 166.

25. Dyke, T. R.; Mack, K. M.; Muenter, J. S. J Chem Phys 1977, 66, 498.

26. Bartmess, J. E.; Scott, J. A.; McIver, R. T., Jr. J Am Chem Soc 1979, 101, 6047.

27. Bordwell, F. G. Acc Chem Res 1988, 21, 456.

28. Larionova, E. Yu.; Vitkovskaya, N. M.; Kobychev, V. B.; Shevchenko N. V.; Trofimov, B. A. Zh Struct Chem 2007, 48, S101.

29. Kobychev, V. B.; Vitkovskaya, N. M.; Schmidt, E. Yu.; Senotrusova, E. Yu.; Trofimov, B. A. Zh Struct Chem 2007, 48, S107.

30. Fujitake, M.; Hayashi, M. J Mol Struct 1985, 127, 21.

31. Kobychev, V. B.; Vitkovskaya, N. M.; Larionova, E. Yu.; Trofimov, B.A. Phosphorus, Sulfur, Silicon Relat Elem 2002, 177, 2931. 